\title{
Core functions for the public health nutrition workforce in Europe: a consensus study
}

\author{
Svandis Jonsdottir ${ }^{1, *}$, Inga Thorsdottir ${ }^{1}$, Susanna Kugelberg ${ }^{2,3}$, Agneta Yngve ${ }^{2,3}$, \\ Nicholas P Kennedy ${ }^{4}$ and Roger Hughes ${ }^{5}$ \\ 'Unit for Nutrition Research, University of Iceland \& Landspitali - The National University Hospital of Iceland, \\ Eiriksgata 29, Reykjavik, Iceland: ${ }^{2}$ Department of Biosciences and Nutrition, Karolinska Institutet, Huddinge, \\ Sweden: ${ }^{3}$ Faculty of Health, Nutrition and Management, Oslo and Akershus University College of Applied \\ Sciences, Oslo, Norway: ${ }^{4}$ Unit of Nutrition and Dietetic Studies, School of Medicine, Trinity College Dublin \& \\ Trinity Centre for Health Sciences, St. James's Hospital, Dublin, Ireland: ${ }^{5}$ School of Health Sciences, Bond \\ University, Gold Coast, Queensland, Australia
}

Submifted 22 December 2011: Final revision received 14 May 2012: Accepted 1 June 2012: First published online 16 July 2012

\begin{abstract}
Objective: To assess and develop a consensus among a European panel of public health nutrition workforce stakeholders (academics and employers) regarding core functions required for effective public health nutrition practice.

Design: A modified Delphi study involving data from two rounds of questionnaires administered among a panel of public health nutrition workforce stakeholders.

Setting: Europe.

Subjects: A panel of fifty-three public health nutrition development stakeholders, including thirty-three academics and twenty employers, sampled from eighteen European countries.

Results: Panellists rated 50\% (19/38) of the initially listed functions as core (i.e. without which public health capacity is limited), using a majority cut-off ( $>50 \%)$. Out of the nineteen core functions seven were categorised under the heading Intervention management, emphasising high agreement on the importance of managing interventions in public health nutrition work. Only one of the identified core public health nutrition functions was rated differently between academics and employers, suggesting consistent identification of core functions between stakeholder groups.

Conclusions: This consensus on core functions of the public health nutrition workforce in Europe can be used to promote a consistent understanding of the role and value of public health nutritionists as a discrete disciplinary sub-specialty of the public health workforce. The convergence of opinions of academics and employers, as well as comparison with previous international studies, indicates that there is a set of core public health nutrition functions transferable between countries that can be used as a benchmark to guide further development of the public health nutrition workforce in Europe.
\end{abstract}

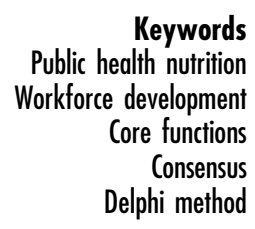

Public health nutrition as a distinct area of disciplinary activity has been a focus of academic and professional discourse in Europe for more than a decade ${ }^{(1-4)}$. More recent consultation with workforce development stakeholders across the European Union member countries and audits of European national action plans relating to nutrition have demonstrated that this academic and professional discourse about the role and value of public health nutrition practitioners has not penetrated the awareness of employers and policy practitioners ${ }^{(5)}$. This is further evidenced by the observation that many countries in Europe have a health workforce which is devoid of practitioners with designated responsibility for action on public health nutrition issues ${ }^{(5)}$.
Previous workforce development research in developed countries outside the European Union have described and demonstrated the importance of a designated public health nutrition workforce in determining the ability to address public health nutrition problems ${ }^{(6-9)}$. This reinforces the recent assessment that the capacity of many European countries to effectively address public health nutrition issues is limited by an under-developed and disorganised workforce, requiring a concerted workforce development effort ${ }^{(5)}$.

Previous workforce development scholarship has suggested that effective public health nutrition workforce development is predicated on a clear understanding of the work required to address public health nutrition 
issues and priorities ${ }^{(8)}$. The cacophony of national action plans relating to nutrition developed in the European Union over the past decade ${ }^{(10)}$ provides some guidance about what needs to be addressed, but little guidance about 'how' and 'by whom', (5).

Intelligence-based approaches to workforce development suggest that it is important to know what the functions (the work) of the workforce should be, in order to develop a workforce with the competencies (knowledge, skills and attitudes) required to perform these functions ${ }^{(8)}$.

Different concepts of what public health nutrition comprises may lead to a lack of focus and inefficient workforce development investments ${ }^{(11)}$. Clarifying the identity of public health nutrition as a professional discipline and codifying roles within the workforce have been key components of workforce development scholarship in countries (Australia, the UK) that have effectively developed public health nutrition as a workforce discipline distinct from other professional groups (e.g. dietitians) ${ }^{(4,12)}$.

Public health nutrition functions have been defined as the work (processes, practices, services and programmes) carried out in order to promote health and well-being in populations through nutrition ${ }^{(8,12)}$. Core functions provide a description of the work necessarily required of public health nutrition practitioners, without which there would be gaps in workforce capacity ${ }^{(13,14)}$. Codifying core public health nutrition functions is important to provide a description of the work required of the practitioners, which can be used as a benchmark to compare with current work practices and workforce characteristics. Strengths and weaknesses in the workforce can be identified to enable strategic improvement of capacity. An understanding of the work required for an effective public health nutrition effort is clearly needed to aid workforce development ${ }^{(8)}$.

Public health nutrition workforce development research in Australia has identified that mapping out core functions can help in the development of the workforce in numerous ways, including:

- clarifying the work of public health nutritionists to assist with workforce role delineation ${ }^{(11,12)}$;

- examining existing workforce practice ${ }^{(15)}$;

- identifying continuing workforce development needs ${ }^{(16)}$; and

- assisting with assessment of workforce preparedness ${ }^{(8)}$.

The value of developing consensus about the core functions of the workforce has been recognised across the public health sector internationally, not just in terms of public health nutrition, including public health ${ }^{(17,18)}$, health promotion and health education ${ }^{(19)}$.

The aim of the present study was to assess and develop a consensus among a European panel of two public health nutrition workforce stakeholder groups, academics and employers, regarding core functions required for effective public health nutrition practice.

\section{Methods}

A modified Delphi study with three rounds of questionnaires was administered among a panel of public health nutrition workforce stakeholders (see Fig. 1). Results on questions focusing on workforce functions from rounds 1 and 2 are reported here. Results from round 3 have been previously reported ${ }^{(20)}$.

\section{Expert panel recruitment}

An email contact list for European public health nutrition workforce development stakeholders was assembled, primarily through snowball sampling and an Internet search. Potential panel members were identified mainly through websites of European universities, official websites of public health nutrition research projects, the European Network for Public Health Nutrition, conferences and workshops related to public health nutrition and through the Nutrition Society website. Some candidates for the Delphi panel were identified through existing professional networks. The final contact list included 159 identified stakeholders across Europe who were formally invited via email to join the pan-European expert panel and participate in the Delphi process. Invitees were asked to self-select to the Delphi panel if they considered that they had in-depth understanding, experience and knowledge regarding public health nutrition as a discipline and practice area. Invitees were also invited to nominate public health nutrition stakeholders who they believed were capable of adding valuable knowledge to the process. Invitees who accepted the invitation received the Delphi questionnaires by email.

\section{The Delphi survey tools}

The Delphi surveys used in each round of the present study were based on instruments previously developed by Hughes ${ }^{(8,21-23)}$ and used for development of consensus among an international panel of public health nutrition leaders, including the European Network for Public Health Nutrition, regarding core public health nutrition workforce functions and essential competencies required for effective public health nutrition practice.

In the round 1 survey, thirty-eight proposed public health nutrition workforce functions were rated on a 4-point Likert scale (always a public health nutrition function (core); often a public health nutrition function; sometimes a public health nutrition function; not a public health nutrition function). These public health nutrition workforce functions were organised into six broad categories: Research, monitoring $\mathcal{E}$ assessment; Ensuring bealthy $\&$ safe environments; Nutrition education $\&$ guidance; Building capacity; Policy processes; and Intervention management (see Table 1).

Definitions for Public bealth nutrition functions and Core public health nutrition functions were presented to the panel members to provide context for the workforce 


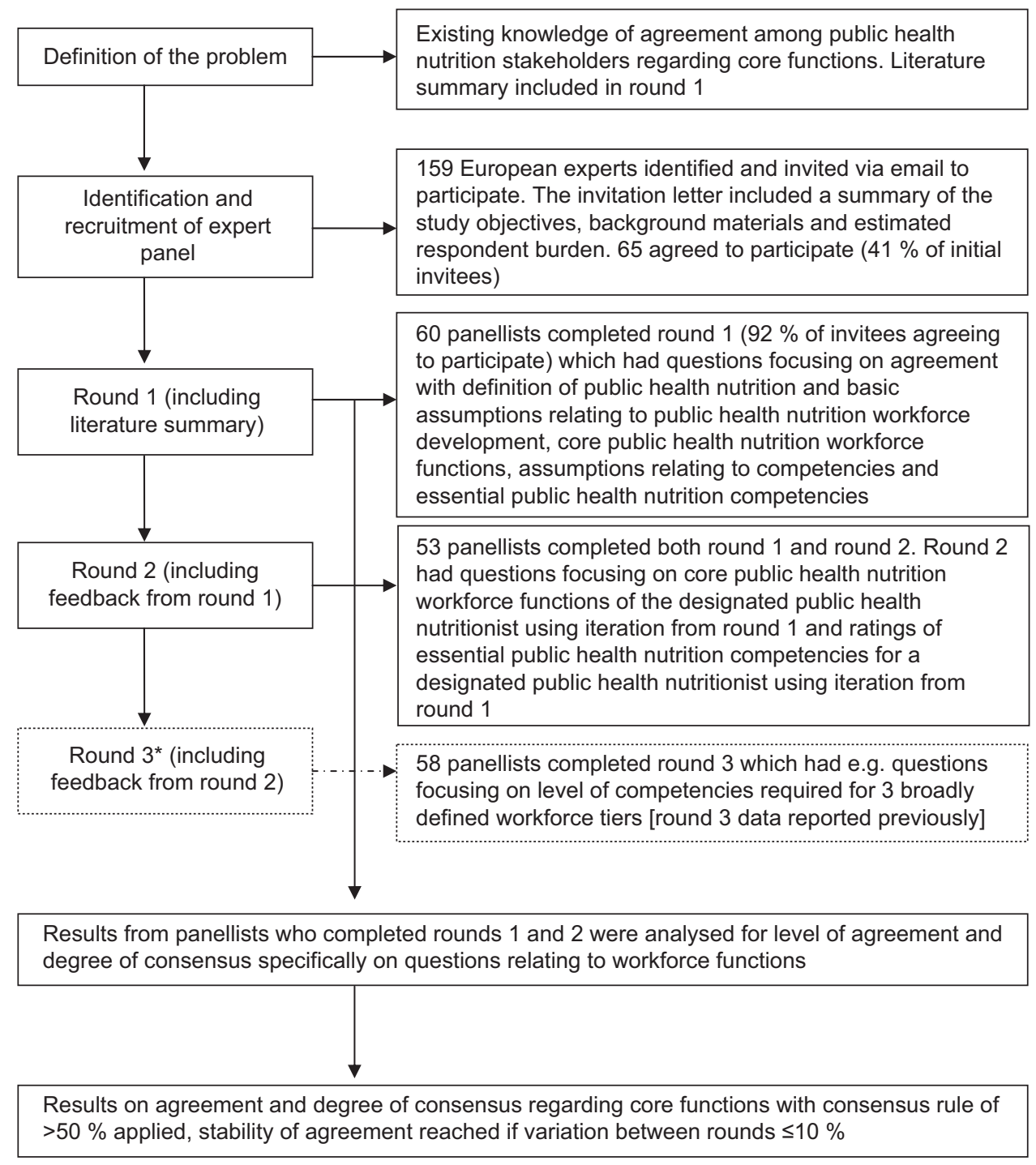

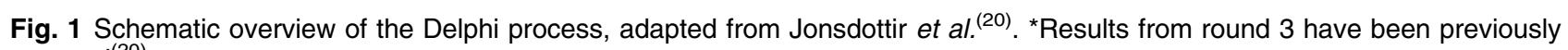
reported $^{(20)}$

development questions. Public health nutrition functions were defined as those activities (processes, practices, services and programs) which are undertaken in order to promote optimal nutrition, health and well-being in populations. Core public bealth nutrition functions were defined as those functions that are regarded as absolutely necessary, without which one would imply gaps in public health nutrition capacity. At round 2, panel members were asked to rate the same functions again but asked to consider the group's previous response distribution from round 1 before giving their answers. After grading proposed workforce functions derived from the literature, panellists were invited to add comments or alternative functions to be incorporated in the next survey.

\section{Definition and stability of the consensus}

Defined consensus definitions were used to judge agreement among the panellists and define when consensus had been developed. The consensus standard was set at $>50 \%$ agreement. The consensus was considered to have reached stability if group ratings on suggested workforce functions varied by $\leq 10 \%$ between rounds. This approach to define stability (i.e. $\leq 10 \%$ response shift) of the consensus has been used in previous studies ${ }^{(22,24)}$.

\section{Data analysis}

Responses to the Delphi questionnaires were entered to Microsoft Office Excel 2003 for storage and imported to IBM SPSS Statistics 20 for analysis. Frequency distributions were compared between survey rounds for questions related to core function rankings. Pearson's $\chi^{2}$ test was used to test for differences in distribution between academic $v$. employer panellists when applicable, but Fisher's exact test was used when expected frequencies were $\leq 5$. The level of significance was set at $P<0 \cdot 05$. 
Table 1 Response distributions (valid \%) for agreement on suggested workforce functions being core public health nutrition functions at round 2, in descending order within each broad category

\begin{tabular}{|c|c|c|c|}
\hline Suggested workforce functions & $\begin{array}{l}\% \text { Shift between } \\
\text { rounds } 1 \& 2\end{array}$ & Round 1 & Round 2 \\
\hline \multicolumn{4}{|l|}{ Research, monitoring \& assessment } \\
\hline Evaluating the effect of policies on nutrition and health & $+21 \cdot 6$ & $60 \cdot 8$ & $82 \cdot 4$ \\
\hline Assessing population needs to determine nutrition programme and service priorities & $+13 \cdot 7$ & $64 \cdot 7$ & $78 \cdot 4$ \\
\hline Monitoring determinants of nutrition and health ${ }^{*}$ & $+17 \cdot 6$ & $47 \cdot 1$ & $64 \cdot 7$ \\
\hline Monitoring nutrition service and programme delivery & $+15 \cdot 6$ & $47 \cdot 1$ & $62 \cdot 7$ \\
\hline Undertaking research on services and programmes (evaluations)† & $-2 \cdot 0$ & $45 \cdot 1$ & $43 \cdot 1$ \\
\hline Monitoring nutrition-related mortality and morbidity† & $+2 \cdot 0$ & $32 \cdot 0$ & $34 \cdot 0$ \\
\hline Identifying nutrition research priorities & $-11 \cdot 8$ & $37 \cdot 3$ & $25 \cdot 5$ \\
\hline Undertaking research on nutrition issues in populationst & $-5 \cdot 9$ & $27 \cdot 5$ & $21 \cdot 6$ \\
\hline Economically evaluating nutrition programmes or problems & $-13 \cdot 7$ & $25 \cdot 5$ & $11 \cdot 8$ \\
\hline \multicolumn{4}{|l|}{ Ensuring healthy \& safe environments } \\
\hline Addressing misinformation about nutrition & $+19 \cdot 1$ & $54 \cdot 9$ & $74 \cdot 0$ \\
\hline Promoting equal access to healthy foodt & $+9 \cdot 8$ & $43 \cdot 1$ & $52 \cdot 9$ \\
\hline Addressing advertising and marketing practices to enable informed food choicest & $+2 \cdot 0$ & $45 \cdot 1$ & $47 \cdot 1$ \\
\hline Promoting equal access to physical activity & $-13 \cdot 7$ & $29 \cdot 4$ & $15 \cdot 7$ \\
\hline Ensuring food safetyt & $-7 \cdot 9$ & $21 \cdot 6$ & $13 \cdot 7$ \\
\hline Ensuring the sustainability of the food supplyt & $-3 \cdot 7$ & $13 \cdot 7$ & $10 \cdot 0$ \\
\hline The protection of safe water suppliest & $-5 \cdot 7$ & $15 \cdot 7$ & $10 \cdot 0$ \\
\hline \multicolumn{4}{|l|}{ Nutrition education \& guidance } \\
\hline Using mass media for nutrition education + & $+7 \cdot 8$ & $45 \cdot 1$ & $52 \cdot 9$ \\
\hline Providing food and nutrition information to individuals and groupst & -0.8 & $42 \cdot 0$ & $41 \cdot 2$ \\
\hline Developing individuals' nutrition knowledge, attitudes and skillst & +0.7 & $37 \cdot 3$ & $38 \cdot 0$ \\
\hline Social marketing of nutrition issues & $-12 \cdot 4$ & $34 \cdot 0$ & $21 \cdot 6$ \\
\hline \multicolumn{4}{|l|}{ Building capacity } \\
\hline Developing community capacity to participate in nutrition issues & $+15 \cdot 7$ & $52 \cdot 9$ & $68 \cdot 6$ \\
\hline Mobilising community action on nutrition issuest & $+2 \cdot 0$ & $49 \cdot 0$ & $51 \cdot 0$ \\
\hline Providing education and training for other health workerst & $-2 \cdot 0$ & $45 \cdot 1$ & $43 \cdot 1$ \\
\hline Building social networks and social support in communitiest & $-9 \cdot 8$ & $29 \cdot 4$ & $19 \cdot 6$ \\
\hline Providing education and training for consumers and community groups & $-11 \cdot 8$ & $31 \cdot 4$ & $19 \cdot 6$ \\
\hline Providing education and training for professionals in sectors other than health & $-17 \cdot 7$ & $37 \cdot 3$ & $19 \cdot 6$ \\
\hline \multicolumn{4}{|l|}{ Policy processes } \\
\hline Assess the impact of public policy on nutrition and health & $+27 \cdot 5$ & $62 \cdot 7$ & $90 \cdot 2$ \\
\hline Advocate for food- and nutrition-related legislation to protect and promote health & $+23 \cdot 5$ & $47 \cdot 1$ & $70 \cdot 6$ \\
\hline Advocate for sustainable and appropriate financing of nutrition services & $+15 \cdot 7$ & $43 \cdot 1$ & $58 \cdot 8$ \\
\hline Review, formulate and promote health legislationt & $+5 \cdot 8$ & $37 \cdot 3$ & $43 \cdot 1$ \\
\hline Enforce food and nutrition legislationt & $-7 \cdot 9$ & $21 \cdot 6$ & $13 \cdot 7$ \\
\hline \multicolumn{4}{|l|}{ Intervention management } \\
\hline Developing strategies to address nutrition issues & $+11 \cdot 8$ & $78 \cdot 4$ & $90 \cdot 2$ \\
\hline Planning nutrition interventions & $+17 \cdot 6$ & $66 \cdot 7$ & $84 \cdot 3$ \\
\hline $\begin{array}{l}\text { Building organisational structures and processes with agencies to } \\
\text { facilitate public health nutrition action }\end{array}$ & $+17 \cdot 7$ & $62 \cdot 7$ & $80 \cdot 4$ \\
\hline Developing intersectoral partnerships to promote nutrition & $+21 \cdot 5$ & $56 \cdot 9$ & $78 \cdot 4$ \\
\hline Evaluating nutrition interventions & $+25 \cdot 1$ & $52 \cdot 9$ & $78 \cdot 0$ \\
\hline Accessing resources to support public health nutrition action & $+11 \cdot 7$ & $47 \cdot 1$ & $58 \cdot 8$ \\
\hline Implementing nutrition interventionst & +8.9 & $47 \cdot 1$ & $56 \cdot 0$ \\
\hline
\end{tabular}

Bolded functions reached the consensus standard, i.e. $>50 \%$ agreement among panel members.

*Significant differences $\left(\chi^{2}, P<0 \cdot 05\right)$ in response distributions between academics $v$. employers at round 2.

tResponse stability achieved, i.e. $\leq 10 \%$ variation in ratings between rounds 1 and 2 .

\section{Results}

\section{Characteristics of the Delphi panel}

Fifty-three stakeholders completed the first two rounds of the Delphi process that focused on core functions. Those panel members came from eighteen European countries and were categorised into two subgroups (employers $v$. academics) based on their current position. Twenty panel members were defined as employers (e.g. working in public health institutes, ministries, private companies, etc.) while thirty-three were defined as academics (e.g. university personnel, employees at research institutes, etc.). A list of all panellists participating in the Delphi process and their country of origin is presented in the Acknowledgement section of the current paper.

\section{Public bealtb nutrition workforce functions}

Panel members were asked to rate thirty-eight proposed public health nutrition workforce functions (Table 1) to assess their agreement on core workforce functions (the work) believed to be important for effective public health nutrition effort at a community level. Ten of thirty-eight (26\%) proposed workforce functions met the consensus criteria ( $>50 \%$ ) for a core function at round 1 . At round 2 , there was an obvious increase in consensus since panel members rated nineteen workforce functions (50\%) as 
core functions. Out of those nineteen core functions, seven clustered under the Intervention management function category, emphasising the importance of intervention management in public health nutrition practice (Table 1). Panellists put relatively low emphasis on proposed workforce functions under the headings of Ensuring bealthy $\&$ safe environments, Nutrition education \& guidance and Building capacity, with twelve of the seventeen proposed functions under these headings not reaching consensus limit at round 2 (Table 1). Despite being invited to suggest alternative or additional functions in round 1 , none were suggested.

Of the nineteen functions rated as 'core' by $>50 \%$ of panellists after round 2 , only four had a variation in response distribution $\leq 10 \%$ between rounds (stability of agreement), with all others increasing agreement of core function rating between rounds. This suggests that the iterative feedback from responses in round 1 has promoted consensus between panellists.

\section{Differences in response distributions of academics v. employers}

Analysis showed significant differences in the response distributions of academics $v$. employers on only one suggestion relating to public health nutrition workforce functions at round 2 (Table 1), i.e. Monitoring determinants of nutrition and bealth, with academics rating it more often as a 'core' function $(78 \cdot 1 \%$ of academics $v .42 \cdot 1 \%$ of employers; $\left.\chi^{2}=6 \cdot 8, P=0 \cdot 01\right)$.

\section{Discussion}

The concept of a 'public health nutrition expert' in the context of workforce development is subjective. Any inadvertent bias in the selection of the panel was limited by asking invitation receivers to self-select if they considered themselves experts, or forward the invitation to whomever they considered an expert. A basic and logical assumption of the sampling method used to develop the Delphi panel was that individuals occupying academic or senior-level professional roles relevant to public health nutrition were 'experts' in the context of public health nutrition workforce development. Panellist self-selection after invitation is also likely to engage individuals who consider themselves to be experienced and knowledgeable in this field. The good panellist retention across the two survey rounds (fifty-three of the sixty initial participating panellists) indicates their high degree of interest and engagement in the topic. The convergence of opinions of academics and employers seen in the current study strengthens the idea of core functions applicable to different surroundings. A known limitation of the Delphi method is that the literature provides limited guidance about how consensus should be defined ${ }^{(25,26)}$.

The list of thirty-eight different functions listed in Table 1 provides a spectrum of work that public health nutritionists may be required to perform in different practice contexts. The nineteen functions identified in the present study as 'core' (i.e. regarded as absolutely necessary, without which there would be gaps in capacity) prioritise functions to help isolate the consistent work expectations of public health nutritionists in the European context. The present study reinforces the findings from earlier Australian and Canadian studies $^{(6,12,21)}$ that the predominant workforce functions of designated public health nutritionists relate to intervention management (the design, implementation and evaluation of population-based nutrition interventions) and analytical functions associated with assessment, monitoring, research and evaluation. This consistency suggests that the core function expectations identified between countries are not dependent on cultural, health system or other differences, and are possibly transferable internationally. The functions listed that did not achieve consensus ( $>50 \%$ agreement) can be interpreted as either not being considered by panellists as core or that these functions are different in terms of importance ratings because of national differences in workforce expectations.

Agreement and a strengthening of consensus from other parts of the world were reached with regard to the core workforce functions for effective public health nutrition practice in the European context. Consensus on the core functions (the work) of the public health nutrition workforce emphasised the importance of analytical and interventionist functions in the context of preventing dietrelated diseases among the population. This consensus enables the development of clear statements about public health nutrition work to inform workforce development and can be used to construct human resource management tools such as position descriptions that can be used to recruit practitioners to clearly defined workforce roles.

\section{Conclusions}

The convergence of opinions of academics and employers in the present study reinforces previous international studies and indicates that there is a set of core public health nutrition functions transferable between countries. This consensus on core public health nutrition workforce functions can be used to promote a consistent understanding of the role and utility of public health nutritionists as a discrete disciplinary sub-speciality of the public health workforce in Europe. The identified core functions can be used to review current workforce practices, develop workforce development tools such as position descriptions and guide further development of the public health nutrition workforce in Europe.

\section{Acknowledgements}

This Delphi study is a part of a pan-European project, JobNut, which was supported by the Leonardo Community 
Vocational Training Programme (agreement number 2003320). The authors declare they have no conflict of interest. S.J. participated in the design of the Delphi study and implemented the study, had a principal role in the Delphi data analysis and reporting and took a lead role in drafting and editing the manuscript. I.T. participated in the survey design and data analysis. A.Y. advised with conceptualising the study, identifying the panel and was the project manager. S.K. contributed to survey design. N.P.K. assisted in developing the expert panel and in editing the manuscript. R.H. advised with conceptualising the study, participated with methods design and data analysis and drafted and edited the manuscript. All authors contributed to the final editing of the manuscript. The generous contributions and input from the following public health nutrition stakeholders and Delphi panel members (country identified in parentheses) is appreciated: Katica Antonic Degac (Croatia); Katherine O'Doherty Jensen, Lotte Holm, Sjurdur Olsen (Denmark); Arja Erkkilä, Irja Haapala, Jaakko Kaprio, Pekka Puska (Finland); Ambroise Martin (France); Andrea Lugasi, Éva Martos (Hungary); Helmut Oberritter (Germany); Theodora Psaltopoulou (Greece); Elva Gísladóttir, Ingibjörg Gunnarsdóttir, Laufey Steingrímsdóttir (Iceland); Cecily Kelleher, Corina Glennon Slattery, Eileen Gibney, Geraldine Quinn, John Kearney, Linda Hogan, Nick Kennedy (Ireland); Domenico Palli (Italy); Albertas Barzda, Algis Abaravicius (Lithuania); Yvette Azzopardi (Malta); Alma van der Greft, Annemiek van Bolhuis, Joop van Raaij (Netherlands); Arne Oshaug, Knut-Inge Klepp, Øydis Ueland (Norway); Lucjan Szponar (Poland); Maria Daniel Vaz de Almeida (Portugal); Cirila Hlastan-Ribic, Jozica Maucec-Zakotnik (Slovenia); Carmen Pérez-Rodrigo, Emilio Martínez de Victoria Muñoz, Gregorio Varela Moreiras, Lluis Serra Majem, Victòria Arija (Spain); Agneta Yngve, Anki Sundin, Annica Sohlström, Gudrun Ahlin, Gunnar Johansson (Sweden); Anne Heughen, Ailsa Welch, Alison Nelson, Barrie Margetts, Claire Schofield, Diane Talbot, Elizabeth Lund, Jackie Landman, Jessica Swann, Kim Procter, Rachel Thompson, Sheela Reddy, Sinead McElhone, Susan Jebb, Wendy Wills (UK).

\section{References}

1. Yngve A, Sjostrom M, Warm D et al. (1999) Effective promotion of healthy nutrition and physical activity in Europe requires skilled and competent people; European Master's Programme in Public Health Nutrition. Public Health Nutr 2, 449-452.

2. Buttriss J \& Landman J (2000) The Nutrition Society: developments in professionalisation. Nutr Bull 25, 361-364.

3. Landman J, Buttriss J \& Margetts B (1998) Curriculum design for professional development in public health nutrition in Britain. Public Health Nutr 1, 69-74.

4. Landman JP \& Wootton SA (2007) Professional regulation of nutritionists: where are we now? Proc Nutr Soc 66, 269-276.

5. Margetts B (2009) Promoting the Public Health Nutrition Workforce in Europe. Final Report of the Jobnut Project. Southampton: University of Southampton.
6. Fox A, Chenhall C, Traynor M et al. (2008) Public health nutrition practice in Canada: a situational assessment. Public Health Nutr 11, 773-781.

7. Haughton B \& George A (2008) The Public Health Nutrition workforce and its future challenges: the US experience. Public Health Nutr 11, 782-791.

8. Hughes R (2003) A conceptual framework for intelligencebased public health nutrition workforce development. Public Health Nutr 6, 599-605.

9. Hughes R (2006) A socioecological analysis of the determinants of national public health nutrition work force capacity: Australia as a case study. Fam Community Health 29, 55-67.

10. Lachat C, Van Camp J, De Henauw S et al. (2005) A concise overview of national nutrition action plans in the European Union Member States. Public Health Nutr 8, 266-274.

11. Hughes R (2003) Definitions for public health nutrition: a developing consensus. Public Health Nutr 6, 615-620.

12. Hughes R (2004) Employers expectations of core functions and competencies for public health nutrition practice in Australia. Nutr Diet 61, 105-111.

13. National Public Health Partnership (2000) Public Health Practice in Australia Today. A Statement of Core Functions, pp. 1-8. Melbourne: NPHP.

14. US Department of Health and Human Services (1997) The Public Health Workforce: An Agenda for the 21st Century. A Report of the Public Health Functions Project, pp. 1-61. Washington, DC: US Department of Health and Human Services.

15. Hughes R (2004) Work practices of the community and public health nutrition workforce in Australia. Nutr Diet 61, 38-45.

16. Hughes R (2003) Competency development needs of the Australian public health nutrition workforce. Public Health Nutr 6, 839-847.

17. Biesma RG, Pavlova M, Vaatstra R et al. (2008) Generic versus specific competencies of entry-level public health graduates: employers' perceptions in Poland, the UK, and the Netherlands. Adv Health Sci Educ Theory Pract 13, 325-343.

18. Yngve A \& Haapala I (2008) Public Health Training In The Context of An Enlarging Europe. Final Technical Report Covering the Period 01/04/2005 to 01/07/2008 Agreement Number - 2004305, pp. 1-37. Stockholm: Karolinska Institutet.

19. Allegrante JP, Barry MM, Auld ME et al. (2009) Toward international collaboration on credentialing in health promotion and health education: the Galway Consensus Conference. Health Educ Behav 36, 427-438.

20. Jonsdottir S, Hughes R, Thorsdottir I et al. (2011) Consensus on the competencies required for public health nutrition workforce development in Europe - the JobNut project. Public Health Nutr 14, 1439-1449.

21. Hughes R (2003) Public health nutrition workforce composition, core functions, competencies and capacity: perspectives of advanced-level practitioners in Australia. Public Health Nutr 6, 607-613.

22. Hughes R (2004) Competencies for effective public health nutrition practice: a developing consensus. Public Health Nutr 7, 683-691.

23. Hughes R (2005) A Competency Framework for Public Health Nutrition Workforce Development, pp. 1-28. Wollongong: Australian Public Health Nutrition Academic Collaboration.

24. Duffield C (1993) The Delphi technique: a comparison of results obtained using two expert panels. Int J Nurs Stud 30, 227-237.

25. Keeney S, Hasson F \& McKenna H (2006) Consulting the oracle: ten lessons from using the Delphi technique in nursing research. J Adv Nurs 53, 205-212.

26. Boulkedid R, Abdoul H, Loustau M et al. (2011) Using and reporting the Delphi Method for selecting healthcare quality indicators: a systematic review. PloS One 6, e20476. 